\title{
A NOÇÃO HEIDEGGERIANA DE ANGÚSTIA E AS ORIGENS DA PSICOPATOLOGIA FUNDAMENTAL
}

Sonia Maria Maciek ${ }^{\star}$

SINTESE - Este ensaio pretende explorar a noção heideggeriana de angústia existencial como suporte epistêmico da concepção psicanalítica de psicopatologia fundamental. Nessa medida 0 estudo apontará, através do conceito de angústia, alguns aspectos que unem filosofia e psicanálise. PALAVRAS-CHAVE - Angústia. Filosofia. Psicanálise. Psicopatologia fundamental.
ABSTRACT - This essay intends to explore Heidegger's concept of existential anguish as epistemic support of the psychoanalytical conception of fundamental psychopathology. In this way the study will show, by means of the idea of anguish, some aspects that link philosophy and psychoanalysis.

KEY WORDS - Anguish. Philosophy. Psychoanalysis. Fundamental psychopathology.

Apesar de suas relações serem ambivalentes, filosofia e psicanálise em alguns pontos podem encontrar-se. O pathos, o sofrimento, as paixões humanas, é um deles. Sófocles e Ésquilo, trágicos gregos que marcaram profundamente o pensamento ocidental com seus textos dramáticos, já tentavam mostrar esse pathos que vem "de longe e de fora" e se apodera do corpo dominando-o. Posteriormente, com a valorização do discurso racional, do logos, os filósofos gregos tentaram abordar esse inominável que se apodera do indivíduo com uma linguagem lógica. Submetida a uma audiência crítica a linguagem do logos buscava encontrar uma posição irrepreensível. Desde então, filósofos tentam explicar, por meio de postulados discursivos, os fenômenos a que o corpo e a alma humana estão submetidos, não como simples acidente, mas como uma característica própria de seu ser.

O inconsciente postulado por Freud, no início do nosso século, como lugar de manifestação do pathos originário, rompe com os modelos tradicionais de entendimento do patológico. Para Freud, as observações objetivas da consciência não são suficientes para captar a totalidade da experiência humana. A teoria psicana-

Psicóloga, psicanalista, doutoranda do Curso de Pós-Graduaçăo em Filosofia da PUCRS.

\begin{tabular}{|l|l|l|l|l|l|} 
VERITAS & Porto Alegre & v. 44 & n. 1 & Março 1999 & p. 187-199 \\
\hline
\end{tabular}


lítica, que tem o inconsciente como um de seus pilares, surge como uma alternativa possível e válida, ao mesmo tempo que instaura um novo paradigma na busca de compreensão do sofrimento fundamental: a psicopatologia do inconsciente. Lugar onde se depositam nossas vivências mais arcaicas como espécie humana, o inconsciente representa uma estratégia de ruptura e de dissolução dos modelos convencionais de entendimento do patológico. A partir da interpretação de manifestações inconscientes, do pathos original, a psicanálise busca compreender 0 processo de desencadeamento de um sofrimento psíquico específico. Portanto, as pesquisas e os estudos psicanalíticos vão além do estudo de uma simples psicopatologia geral, examinam o próprio sofrimento psíquico, a manifestação do patológico no homem, para a partir daí determinar a condição de possibilidade de qualquer sofrimento psíquico específico. Assim, o conceito de psicopatologia da psicanálise que parte da psicopatologia fundamental é mais amplo que o da psiquiatria, na medida em que ela fornece um quadro referencial que se poderia chamar de supra-empírico, metapsicológico, justamente porque se trata de um pathos fundamental. Este ensaio pretende explorar a noção de angústia existencial como suporte epistêmico dessa concepção de psicopatologia. Nesta medida o estudo analisará, através da angústia, uma questão que une filosofia e psicanálise.

Thomas Szasz em seu livro O mito da doença mental relata que a doença mental, em toda sua história, sempre esteve associada, muito proximamente, à doença física, orgânica. A lepra e a sífilis, na Idade Média, eram doenças de loucos e mendigos. Ainda no século passado, o paciente esquizofrênico era visto como aquele que inventa histórias. Uma pessoa só era considerada doente se houvesse alguma coisa de errado com o seu corpo. As pessoas que "simulavam" doença, ou melhor, aquelas que se pensava que simulavam doença, eram considerados falsos doentes e, portanto, não lhes era oferecido um tratamento adequado.

Freud e os médicos que trabalhavam com ele na época criaram um novo sistema de classificação da doença mental, especialmente no que diz respeito à histeria e à doença simulada. A histeria era ainda vista como um tipo de simulação de doença, mas uma forma muito especial: o paciente não sabia que estava simulando.

Os pacientes histéricos representavam um grande desafio para psiquiatras e neurologistas da época. Freud soube dos trabalhos pioneiros de um neurologista francês, chamado Charcot, que coordenava a clínica psiquiátrica Salpêtrière em Paris e foi acompanhar, durante um período, seus trabalhos. Quando retornou a Viena em 1886, procurando dar continuidade ao trabalho que iniciara com Charcot, centrou seus estudos na histeria. Sua meta era criar uma prática que tratasse as chamadas doenças nervosas. Isso significava um grande desafio, pois, a ciência médica estava interessada apenas nas aflições do corpo. Os problemas de ordem pessoal - da vida ou da existência humana - eram ignorados ou tratados como se fossem manifestações de doenças físicas.

1 Szasz, Thomas. O mito da doença mental. Sāo Paulo: Zahar, 1983, passim. 
A medicalização de problemas pessoais estava enraizada, em parte, no perene dilema com que os médicos encaravam os chamados pacientes histéricos, ou seja, decidir se o paciente estava com uma doença orgânica ou "apenas" histeria. Embora, originalmente, isso envolvesse uma distinção entre doença real e doença simulada, para Freud significava distinguir doença funcional de doença orgânica, ou doença mental de doença física - e, em especial, doença neurológica de histeria de conversão. Era evidente que os casos tratados por Freud nenhum apresentava desordens fisiológicas ou anatômicas; no entanto, isso não impedili que ele formulasse hipóteses orgânicas com respeito às "causas" dessas "doenças".

A teoria psicanalítica da histeria e da neurose, formulada posteriormente, veio assim preencher uma lacuna. Com a psicanálise as doenças que se caracterizavam por ser uma perturbação no estado estrutural ou funcional do organismo foram avaliadas através de novos critérios: a incapacidade e o sofrimento.

A chegada aos consultórios de pacientes deprimidos, neuróticos, fronteiriços, portadores de distúrbios de caráter ou falhas profundas na organização do psiquismo impulsionaram os estudos freudianos quanto à validade dos pressupostos vigentes na época, no que se refere ao psicopatológico e seu método de abordagem clínica. Diante das dificuldades em trabalhar com as novas organizações patológicas que se apresentavam, a psicanálise como teoria e terapêutica se mostrou, de acordo com Freud, como "um trabalho pastoral secular", isto é, um campo do saber que se caracterizava pela vigilância constante da abrangência de suas categorias bem como um estar atento permanente ao sofrimento do paciente e de como isso se apresenta. Assim, dentre os discípulos de Freud houve aqueles que, procurando adequar cada vez mais o paradigma que surgia, deram enfoques e rumos diferentes à intuição fundamental freudiana criando, dentro da própria psicanálise, diferentes modos de abordagem do sofrimento psíquico.

Salientaremos alguns desses enfoques que deram novos rumos ao impulso fundamental de Freud, sempre buscando ampliar e redimensionar os conceitos e hipóteses "clássicos". O próprio Freud abriu caminho para essas inovações ao reformular, durante as várias etapas de evolução da teoria psicanalítica, conceitoschave. O conceito de angústia, analisado em 1894 no artigo As neuropsicoses de defesa, segue um enfoque profundamente revisto e reformulado mais tarde no artigo Inibição sintoma e angústia de $1926 .{ }^{2}$

Na primeira abordagem da angústia Freud descreve alguns casos, analisados por ele, com o intuito de diferenciar a neurastenia de uma síndrome particular que chamou "neurose de angústia". No texto escreve o seguinte: "[...] os sintomas da neurose de angústia são como que sucedâneos da ação específica que falta após a excitação sexual, [...] sugerimos a seguinte resposta: a psique mergulha no afeto de angústia quando se sente incapaz de liquidar, pela reação correspondente, uma

2 Laplanche, J. A angústia. São Paulo: Martins Fontes, 1987, p. 14.0 autor descreve a evolução da teoria freudiana da angústia que se inicia com o texto "La naissance de la psychanalyse" obra de 1890, passa pelos textos da "Métapsychologie", particularmente "Réfoulement" e "Deuil et mélancolie", até chegar a "Inhibition, symptôme et angoisse" e "Abrégé de psychanalyse", texto tardio de Freud. 
tarefa proveniente do exterior (perigo), cai na neurose de angústia quando se vê incapaz de regular a excitação de origem endógena (sexual). Comporta-se nesse caso como se projetasse essa excitação no exterior". E ainda, "[...] o que leva à neurose de angústia são fatores que impedem a elaboração psíquica da excitação sexual somática. As manifestações da neurose de angústia sobrevêm quando a excitação sexual somática desviada para fora do psiquismo se consome de maneira subcortical, em reações totalmente inadequadas." "3sto quer dizer: do recalcamento da libido não descarregada sobreviria a neurose de angústia. Conclui-se, portanto, que a neurose de angústia, subjacente aos estados de ansiedade comumente observados, proviria de uma transformação direta da libido em angústia.

Passando por um longo percurso e por muitas nuanças o estudo da angústia chega, na fase mais fecunda da teoria freudiana, a uma concepção metapsicológica que eleva a produção de angústia à dimensão de um sinal e faz do eu o locus privilegiado dessa operação. Isso acontece devido a uma espécie de inversão da dinâmica proposta anteriormente para caracterizar as neuroses: não é mais o recalcamento que produz a angústia, pelo contrário, é a angústia que produz o recalcamento. Como sinal de desprazer, percebido pelo eu, ela permitiria a este utilizar diversos modos de defesa, entre os quais, em particular, o recalcamento. Nesta concepção reformulada, a angústia aparece plenamente funcional na economia do sujeito. Sendo constitutiva da organização psíquica, ela deixa entrever, de modo mais geral, a fonte dos afetos nos sedimentos de acontecimentos traumáticos bem arcaicos e estes, como Freud dá a entender em Inibição sintoma $e$ angústia, seriam então evocados como símbolos mnêmicos no curso de situações similares.

As grandes correntes psicanalíticas pós-freudianas adquirem um referencial teórico, às vezes, muito diferente do proposto por Freud com relação à origem da angústia. Melanie Klein, por exemplo, colocou sua atenção nos efeitos devastadores do superego, alimentado pela agressividade e pelas fantasias sádicas. Daí a sensibilidade para a angústia e o modo de interpretação que privilegia os conteúdos inconscientes na sua função anșiogênica, que visa produzir a mudança psíquica mediante a interpretação minuciosa das fantasias inconscientes e a maneira pela qual elas organizam a situação transferencial.

Lacan retomando os conceitos freudianos, mas vivendo sob influências que marcaram o contexto intelectual de sua época, mais especificamente o estruturalismo francês, dá-lhes outra configuração. Com o auxílio de categorias filosóficas hegelianas e posteriormente heideggerianas elabora um arcabouço teórico sensivelmente diferente daquele dos ingleses da corrente kleiniana. Para ele, a angústia resultaria menos de uma ressurgência traumática que de uma vacilação da estrutura psíquica, no sentido que esta tenderia a se apropriar de momentos regressivos de sua formação. É sempre nas profundezas do real que surge a ameaça, aquela que assinala o perigo da ressurgência da desordem, evoca de outra

3 Freud, S. Obras completas. Las neuropsicosis de defensa, 1894. Madrid: Editorial Biblioteca Nueva, 1948 , v. 2, p. 175. 
maneira pelo retorno ao seio materno. De resto será o Outro, portador do significante, que atestará o corte necessário para a constituição do sujeito numa operação de alienação que este se esforçará por desfazer. A angústia encontrará aí sua origem; e, não podendo expressar esse momento eminentemente metapsicológico através da linguagem, animará a dialética do desejo que não cessará de fazer o sujeito perguntar a si mesmo sobre o que ele representa para o desejo do Outro. "A função angustiante do desejo do Outro está ligada ao fato de eu não saber que objeto "a" sou para esse desejo."4 Ainda no mesmo seminário Lacan afirma: "[...] a interpretação que damos diz respeito sempre à maior dependência dos desejos uns em relação aos outros. Mas não é aí que está o enfrentamento da angústia. Não há superação da angústia senão quando o Outro é nomeado."5

Lacan não foi o primeiro a usar, como recurso metapsicológico, o auxílio de categorias filosóficas no desenvolvimento de sua teoria psicanalítica. Muito antes dele, um jovem médico psiquiatra, contemporâneo de Freud e descendente de uma família de médicos dedicada à doença mental, chamado Ludwig Binswanger, já havia percebido a possibilidade de um trabalho produtivo nessa associação. Quando concluiu seus estudos em Lausane e voltou para Heidelberg para dar continuidade à orientação familiar e suceder o pai na direção da clínica Bellevue, viu na fenomenologia de Husserl e sua proposta de "ver tudo para que o verdadeiro possa se mostrar", 6 uma atitude de grande relevância que poderia conduzi-lo a novos caminhos ainda não percorridos pela psicanálișe. No seu livro Sonho e existência (1930) tenta fundir a interpretação dos sonhos em psicanálise e a consideração dos modos fundamentais da existência humana, segundo o método fenomenológico de Husserl e a doutrina do Dasein como "ser-no-mundo" de Heidegger.

A filosofia heideggeriana, mais especificamente a analítica existencial, é explorada por Binswanger como interpretação do sentido do ser e isto possibilita poder traduzir o pensamento de Heidegger também no domínio das possibilidades psiquiátricas e psicanalíticas da existência. Ele introduz suas questões pelo campo daquilo que em psicanálise se chama metapsicologia, teoria geral da psique ou do aparelho psíquico.?

Binswanger exigia de Freud uma interpretação de sentido da existência que a teoria psicanalítica, devido a seu pressuposto, não podia dar. Este sentido foi encontrado na analítica existencial heideggeriana. Com Heidegger, Binswanger introduz um modo de perguntar sobre a essência de um fenômeno no universo

4 LACAN, J. A angústia. Seminário 1962-63. Recife, Publicação para circulação interna do Centro de Estudos Freudianos de Recife, 1997, p. 87-89.

5 Idem, p. 89.

6 HUSSERL, E. A idéia da fenomenologia. Lisboa: Ediçōes 70, 1986, passim.

7 Para se poder avaliar a importância da aproximação de Binswanger da obra de Heidegger e julgar o papel que desempenhou a analítica existencial para o surgimento da Daseinanalyse, se deveria analisar a evolução da teoria binswangeriana e expor as estratégias utilizadas para converter as categorias heideggerianas em conceitos de uso empirico. Iria além das intenções desse trabalho apresentar esses diversos aspectos da incorporação de conceitos filosóficos ao campo de investigação teóriça e às interpretações da clínica. 
psicopatológico sem ter que, necessariamente, recorrer a uma nova categoria metafísica como resposta. Assim, o horizonte filosófico que permite compreender a analítica de Binswanger é, sobretudo, o pensamento de Ser e tempo (1927) e a analítica existencial.

Freud fizera uso, em sua teoria metapsicológica, de uma "mitologia" assentada, em última análise, num fundamento biológico. O projeto de Binswanger supera a base biológico-empiricista recorrendo a uma antropologia a priori, existencial. Como conhecedor do pensamento de Freud e Heidegger, Binswanger identificou, em ambos, interesses que, apesar de serem de procedência distinta, dirigiam-se, em primeiro plano, ao modo de ser-no-mundo, às "condições humanas". Os pressupostos, no entanto, eram diferentes. Assim como para Freud o que aparece em primeiro plano é a natureza - e não o homem - Heidegger substitui o conceito de homem pelo conceito de Dasein. Freud não explicita seus pressupostos. Nisso permanece devedor a seu tempo. Mas é guiado por uma hipótese que o conduz para além do biologismo no núcleo da psicanálise. Aí está o que nenhuma leitura de Freud pode passar por alto. Ele vislumbra novos horizontes sem abandonar a intuição básica da psicanálise. Heidegger, pela analítica do cotidiano, estabelece o espaço que permite dar um suporte à intenção freudiana: as estruturas existenciais.

Binswanger pergunta-se por um fundamento da investigação psicopatológica que para além do método possibilite a passagem da teoria à práxis na investigação psiquiátrica-psicanalítica empírica. Neste sentido, a analítica existencial não forneceu à psiquiatria e à psicanálise apenas um novo fio condutor metodológico em suas pesquisas, mas abriu também o caminho para sua autocompreensão científica que só podia vir do horizonte da fenomenologia.

A perspectiva heideggeriana aponta para o fato de que uma ciência só poderá compreender a si mesma se perceber que elementos estão pressupostos em seus conceitos fundamentais: a questão da compreensão, o sentido do ser, a constituição fundamental do Dasein, como Heidegger o analisa em Ser e tempo.

Assim, a utilização de um método filosófico que coloque a questão do sentido do ser, do modo de ser-no-mundo, pode ser a condição para tal percepção. Todo o espaço de descrição do âmbito da psicanálise e da psiquiatria foi situado por Binswanger no quadro da interpretação da analítica existencial. Por isso, ele termina por aceitar o nome Daseinanalyse para a sua concepção.

A evolução ocorrida em nosso século na psiquiatria, na psicologia e por conseqüência nas técnicas psicoterápicas, fortemente influenciadas pela teoria psicanalítica, deve-se ao interesse que psiquiatras e psicanalistas demonstraram por questões de ordem filosófica, uma vez que as perturbações que ocorrem no homem são uma possibilidade intrínseca da condição humana e não um simples acidente. O psicopatológico não pode ser entendido a partir de um comportamento normal o qual é sobredeterminado a partir de certas características. O homem, como o ser que compreende o ser, busca entender o seu estar no mundo e nele basear as paixões e os sofrimentos da existência concreta. Assim, quando 
Hegel diz que "o homem é um animal doente" compreendemos que ele pretende dizer, entre outras coisas, que a doença, a angústia, a melancolia, a loucura são um destino possivel de seu ser mesmo. A possibilidade do psicopatológico e a possibilidade da criação são condições que decorrem do poder-ser humano.

Desde a época de Freud constata-se um movimento oscilatório entre períodos de grande entusiasmo pela teoria - que coincidem com os momentos de maior criatividade - e períodos "depressivos" que são frutos dos resultados clínicos obtidos desses avanços teóricos. Disso provém a fascinação que suscitaram os novos enfoques teóricos do pós-Freud, Melanie Klein, Lacan, Binswanger e alguns outros. $\mathrm{O}$ analista esperava que novos elementos acrescentados à teoria psicanalítica viriam dar fim à distância que separa teoria e prática. Mas a espera não acabou, pois permanece ainda aberta a questão de como operar, no exercício prático da psicanálise, a ligação entre o já-conhecido de uma teoria e o ainda nãoconhecido que o discurso do analisante traz no ir e vir do tratamento.

Analisaremos a seguir a angústia como modo fundamental de ser, para lançar luz nessa questão. Irá afirmar-se que existe o indizivel, o não-comunicável naquilo que vivemos como experiência.

Se a afirmação de que "a ciência não é ciência, em pleno sentido do termo, enquanto não saiba sobre que bases apriorísticas, sobre que fundamento se constitui"" for consistente e mais a afirmação de Gadamer de que "à essência da ciência moderna corresponde uma metafísica oculta", ${ }^{9}$ temos que nos esforçar na tentativa de determinação filosófica do patológico para que esteja mais além de uma simples distinção entre soma e psique.

No livro Seis estudos sobre Ser e tempo, Stein confirmando essa posição escreve: "Filósofos não têm, propriamente, a tarefa de apresentarem soluçōes contrafáticas para questőes que podem e devem ser resolvidas faticamente. Mas, usando expressões em voga, a filosofia pode não apenas contribuir para a lógica da descoberta, senão também para o contexto da descoberta e isso significa abrir caminhos para o pensamento científico." 10 Segundo esse princípio serão examinados alguns aspectos analíticos existenciais da angústia, postulados por Heidegger no parágrafo 40 de Ser e tempo.

Com a analítica existencial Martin Heidegger inaugura um novo paradigma. "Ao contrário de Descartes que encontrou no cogito sum o lugar das idéias claras e distintas Heidegger privilegia o sum. Para ele o cogito ergo sum de Descartes é uma hipérbole antropomórfica e racionalista. O inverso é que é verdadeiro 'sou logo penso."11 A existência é a condição necessária precedente e possibilitante do pensamento. Como é, então, que o mundo chega a nós? O mundo vem a nós,

8 De WAELHENS, A. A psicose. Ensaio de interpretação analítico-existencial. Rio de Janeiro: Jorge Zahar, 1990, p. 143.

9 GADAMER, H. G. Verdade e método. Petrópolis: Vozes, 1997.

10 STEIN, Emildo J. Seis estudos sobre Ser e tempo. Petrópolis: Vozes, 1988, p. 94.

11 MACIEL, Sonia M. Corpo invisivel. Porto Alegre: EDIPUCRS, 1997, p. 43. 
responde Heidegger, sob a forma e o modo de coisas. Essas coisas são os inumeráveis entes, objetos que o Dasein encontra e que vão caracterizar, conforme o lidar com elas, o modo de ser do Dasein, o ser-no-mundo, o estar-aí.

Através da analítica existencial e dos modos de aparecer do constructo estaraí são lançadas as novas bases de uma teoria do real. Com o novo paradigma Heidegger quer colocar o lugar da verdade através de uma estrutura prática que ele chamará "estar-no-mundo". "Por um mistério de suprema concretude revelanos todo o ser-no-mundo, toda a significação do ser-no-mundo de uma cadeira, de um par de sapatos. Uma total abertura à verdade integral das coisas sobressai." 12 Este novo modo de articular o fundamento último é uma virada na concepção tradicional de homem. Com a substituição da definição tradicional, racionalista, de homem, surgem conseqüências importantes na concepção de realidade (ontologia) bem como na de conhecimento (epistemologia).

No parágrafo 40 de Ser e tempo Heidegger estabelece a angústia como o Cogito da existência. Ela é uma disposição afetiva fundamental do Dasein. A angústia como disposição fundamental remete à inversão heideggeriana no paradigma das teorias da representação. Ele não segue a linha mentalista das teorias da consciência. O conceito de consciência é substituído pelo conceito de abertura. No livro Seminário sobre a verdade, discutindo a mudança paradigmática heideggeriana, Stein escreve o seguinte: "Essa inversão se faz em função da grande questão de Heidegger de qual seja o ponto de partida da filosofia, de qual seja o lugar da verdade. Esse lugar é o cogito da angústia. Assim como o cogito cartesiano é o cogito do método, a angústia é o cogito do método de Heidegger."13

A angústia acontece no ser-no-mundo, "a angústia se angustia no ser-nomundo como tal". ${ }^{14}$ Para Heidegger, o nosso ser-no-mundo é um "ser lançado". Não há nada de místico ou metafísico nesta posição. O mundo no qual somos lançados, sem escolha pessoal, sem conhecimento prévio, já estava aí antes de nós e aí estará depois de nós. O nosso Dasein (ser-no-mundo) é inseparável dele. Mas a relação não é causal, não é como nos modelos idealistas, a nossa consciência constrói o mundo. A expressão "ser-lançado" visa sugerir a facticidade de ter sido entregue. Não sabemos para que fim fomos lançados na existência a não ser no que se refere à morte. No entanto, o Dasein tem que aceitar essa "presentidade", tem que assumir sua própria existência.

Enquanto ser-no-mundo o Dasein opera compreensivamente, isto é, visa um sentido para os entes com os quais lida. Conhecer é uma espécie de ser. "O perceber" o que é conhecido não é uma atividade da consciência, mas é uma forma de "ser-com". No lidar com os entes o "ser-aí" se vê em situação, junto aos entes "intramundanos". Dai decorre o que Heidegger chama de "fuga" de si mesmo, o Dasein "de-cair" no impessoal, no "mundo" das ocupações. No entanto, nem sempre o retirar-se para o mundo das ocupações significa "fuga". Caráter de fuga

12 STEINER, G. Heidegger, Lisboa: Opus, 1990, p. 77.

13 STEIN, Ernildo J. Seminário sobre a verdade. Petrópolis: Vozes, 1993, p. 83.

14 HEIDEGGER, Martin. L'être et le temps. Traduit par Rudolf Boehm et Alphonse De Waelhens. Paris: Gallimard, 1964, p. 228. "Ce qui angoisse l'angoisse est l'être-au-monde comme tel." 
tem apenas o retirar-se baseado no temor daquilo que desencadeia o temor, isto é, do ameaçador. ${ }^{15}$ Mas se aquilo que o temor teme é um ente intramundano o "com que" da angústia é totalmente indeterminado. Mas o caráter mais profundo, mais original é o fato de o ameaçador não se encontrar em lugar algum. O que se espreita não é isso ou aquilo, também não é a totalidade do que é simplesmente dado no sentido de uma soma e sim a possibilidade de tudo que está à mão, isto é, do próprio mundo. ${ }^{16}$

Heidegger argumenta que, quando a angústia passa, costumeiramente, se diz "propriamente não foi nada"17 mais isto é realmente falar do que onticamente já foi. No cotidiano se discute o manual, a manualidade dos utensílios, mas o com que da angústia não tem a ver com o manual. É aí que o filósofo descreve o que entende por Dasein autêntico e inautêntico, pois falar de utensílios é inferior à existência de "outros". O "eu" nunca está sozinho na sua experiência do Dasein. "O encontrar-se com outros não é um atributo contingente, subordinado da subjetividade; é um elemento essencial integrante das realizações recíprocas de ser e mundo. O modo determinante segundo o qual nos deparamos com o outro é, sobretudo, no trabalho". ${ }^{18} \mathrm{O}$ mundo no qual o nosso Dasein se encontra lançado e do qual faz parte possui outros. A "mundaneidade do mundo" é de tal teor que a existência de outros é absolutamente essencial para a sua "facticidade", para "ser-aí". Compreender a presentidade de outros é existir. Realizamos o nosso próprio Dasein no ser-uns-com-os-outros. "Vimos à existência, não nas e segundo as nossas condições, e sim em referência, em relação aos outros."19

O Dasein inautêntico não vive como ele próprio e sim como "eles" vivem, ou melhor, quase não vive de todo. "É vivido" numa armação oca de valores impostos, anônimos. Na existência inautêntica estamos constantemente com medo (do que os outros dizem, do que eles decidirão para nós, de não correspondermos aos padrões de sucesso material, embora nós mesmos não tenhamos feito nada para que esses padrões fossem estabelecidos). O medo dessa ordem é Furcht. Faz parte do fluxo banal, do pré-fabricado. Angst é totalmente diferente. Angst é o que torna problemático, digno de questionamento o nosso ser-no-mundo. Angst é um sinal de autenticidade, de repúdio do "ser-eles", pertence essencialmente ao ser do Dasein como ser-no-mundo.

O Dasein se angustia diante do nada, da ausência de sentido. Do ter que abrir-se para o novo. Nessa "ausência inócua de um acontecer sem mundo, somos invadidos por um sentimento de inquietação. Sentimo-nos literalmente unhei-

15 Idem, p. 228. "Or tout évitement de [...], toute a-version de [...] ne sont pas nécessairement une fuite. Mais l'évitement, fondé sur la peur, de ce que la peur révèle, de ce qui est menaçant, a un caractère de fuite."

16

Idem, 229. "Ce qui nous serre la gorge, ce n'est donc ni ceci ni cela, mais ce n'est pas davantage la somme de tout ce qui subsiste, c'est la pssibilité même de l'étant disponible en tant que tel, c'està-dire le monde".

17 Idem, 230. "Une fois l'angoisse passé, le discours cotidien a coutume de dire qu'au fond ce n'était rien du tout."

18 Steiner, op. cit., p. 80.

19 Idem, p. 81. 
mlich, "sem casa", "desalojados". "Se, portanto, o nada, ou seja, o mundo como tal, se apresenta como aquilo com que a angústia se angústia, isso significa que a angústia se angústia com o próprio ser-no-mundo."20 Isso acontece quando da familiaridade surge o estranho, o diferente, aquilo que quebra a cotidianidade. Dessa ausência de sentido, como possibilidade fundamental, surge a angústia e, a partir dela, o Dasein busca constituir novo sentido. "Angustiar-se abre, de maneira originária e direta, o mundo como mundo. Não é primeiro a reflexão que abstrai do ente intramundano para só então pensar o mundo e, em conseqüência, surgir a angústia nesse confronto. Ao contrário, enquanto modo da disposição, é a angústia que pela primeira vez abre o mundo como mundo." 21

A angústia enquanto disposição fundamental do Dasein empreende uma abertura. A disposição revela "como se está". "Na angústia se está estranho. Com isso se exprime, antes de qualquer coisa, a indeterminação característica em que se encontra o Dasein na angústia: o nada e o 'em lugar algum'."22 Essa estranheza persegue continuamente o Dasein e isso faz com que por vezes se perca no impessoal, no "ser-eles". O modo como o Dasein enfrenta a estranheza é o desvio para a decadência que esconde o não sentir-se em casa. Talvez isso seja o enigma da existência e por isso o homem está em constante fuga de si mesmo, dominado pela tendência para o encobrimento de uma existência inautêntica. "Na questão da angústia, Heidegger mostra porque o homem foge de sua condição, porque ele não se assume na sua totalidade: ser-diante-de-si-mesmo, já ser-em, ser-junto-àscoisas." 23

Heidegger diz que é a partir do sentimento de situação que podemos analisar a angústia como função metodológica fundamental e que não é no mascaramento da angústia, no fugir para os entes disponiveis do cotidiano que lhe retiramos a característica de ser um sentimento fundamental. ${ }^{24}$ É no relacionar-se (comportar-se) com os entes disponiveis no presente que o Dasein tende para uma relação de encobrimento. A dimensão do presente tende a encobrir as dimensões de futuro e passado que revela a totalidade finita. O Dasein não tem escolha, só tem que ser, não pode voltar atrás, ao passado e diante de si está a morte, o futuro. Dois limites existenciais que o ser-aí tem que suportar como característica de seu modo-de-ser.

20 Heidegger, op. cit., p. 229-230. "Et si donc ce qui angoisse l'angoisse apparait être le rien, c'est-àdire le monde comme tel, cela signifie que ce qui angoisse l'angoisse est l'être-au-monde luimême."

21 Idem, 230. "S'angoisser révèle donc originellement et directement le monde comme monde. Ce n'est pas que quelque réflexion éliminerait l'étant intramondain par voie d'abstraction pour ne laisser subsister que la pensée qui ensuite ferait surgir l'angoisse; tout au contraire, l'angoisse en tant que mode du sentiment de la situation révèle originellement le monde comme monde."

22. Idem, 231. "Que l'angoisse en tant qu'elle est un sentiment fondamental de la situation soit, et en telle manière, révélatrice, nous en trouvons une indication non prévenue dans l'explication et le disours quotidiens de l'être-là. Ainsi qu'on l'a vu plus haut, le sentiment de la situation révèle 'où l'on en est'. L'angoisse rend étranger. Ceci exprime en premier lieu l'indétermination originel de la situation ressentie par l'être-là dans l'angoisse: le rien et nulle part."

Heidegger, op. cit., 233. “Car ce n'est certes pas la rareté du phénomène d'angoisse qui pourrait lui retirer le privilège d'assumer pour l'analytique existentiel une fonction méthodologique fonfamentale. Tout au contraire, cette rareté souvent masquée par l'explication publiquement établie du "on', peut se révéler dans ce sentiment fondamental de la situation selon un sense originel." 
É a partir dessa estrutura, do modo-de-ser do Dasein, que a noção de angústia fundamental nos leva à idéia de aprendizagem pelo sofrimento. Sofrimento como uma característica essencial do modo-de-ser-no-mundo, do sentimento de situação diante da finitude do qual nasce a angústia. O phatein não é apenas um sofrer suportando algo, mas deve ser visto como um estado existencial no qual desde sempre estamos submetidos: a condição de (ter que) ser-no-mundo. Desse modo a psicopatologia pode ser pensada primeiro como fundamental, isto é, como condição de possibilidade de qualquer sofrimento psíquico determinado. Isto significa que a estrutura psíquica singular será determinada a partir de como suportamos esse phatos original. As reações que cada indivíduo desenvolverá para suportar as manifestações do estranho, da angústia será em graus diferentes e, portanto, irá determinar ou não a perturbação na relação de objeto

Segundo Gadamer, Ésquilo na tragédia grega reconheceu o significado metafísico desse phatos existencial, dessa fórmula que expressa toda historicidade que cada indivíduo carrega em sua singularidade, experiência do "aprender pelo sofrer". "Esta fórmula não significa somente que nos tornamos inteligentes através do dano e que somente no engano e na decepção chegamos a conhecer mais adequadamente as coisas. [...] Ésquilo pensa mais que isso. Refere-se à razão pela qual isto é assim. O que o homem deve aprender pelo sofrer não é isto ou aquilo mas a percepção dos limites de ser homem, a compreensão de que as barreiras que nos separam do divino não podem ser superadas". ${ }^{25}$

\section{III}

Do que foi dito até agora podemos concluir o seguinte:

1) Foram usadas estratégias para mostrar que apesar de partir de um biologismo, de um puro pensamento objetivante a intuição freudiana, desde o início, evoluiu ultrapassando radicalmente a visão mecanicista. Aproximando as duas versões da teoria freudiana da angústia percebe-se que ela avança no sentido de superar o nível fisicalista para chegar a atingir o que está, realmente, em questão: o elemento supra-empírico.

2) Binswanger consegue superar a explicitação puramente psiquiátrica determinista das doenças mentais, introduzindo um elemento estrutural fundante, condição de possibilidade de qualquer patologia. Ele passa a ver o patológico a partir de uma nova dimensão, isto significa dizer que é de uma perturbação da existência que acontece a perturbação na relação de objeto. Os questionamentos pelo sentido da existência proporcionam um avanço na teoria psicanalítica na medida que Freud, instigado pelos novos horizontes que Binswanger aponta, se vê diante da tarefa de redimensionar o conceito de angústia baseado numa simples representação de um acontecimento traumático. O recurso da analítica existencial remete a um outro nível de experiência que estamos submetidos como ser-nomundo. O segundo conceito de angústia, resultado da intuição freudiana, foi

25 Gadamer, op. cit., p. 525-6. 
explorado mais detalhadamente por Binswanger possibilitando à psicanálise uma nova leitura paradigmática: a Daseinanalyse. A nova problematização que aconteceu a partir da analítica existencial heideggeriana mostra os novos pressupostos que devem ser considerados. A questão da existência e, portanto, a questão da angústia devem ser pensados para além da relação sujeito-objeto, num espaço supra-empírico anterior que possibilita aquilo que Freud chama de sintoma neurótico ou histérico.

3) As análises que fiz do patológico exigiriam explicitações bem mais detalhadas a partir dos pressupostos colocados por Heidegger. Entretanto, o exame feito até agora pretende já ter contribuído para aquilo que ainda permanece tarefa ampla: a desconstrução dos conceitos e da compreensão metafísica que está na origem da teoria psicanalítica. Stein escreve o seguinte referindo-se à desconstrução de conceitos como via para um melhor entendimento de expressões não totalmente adequadas: "A melhor maneira de localizarmos o problema introduzido por uma expressão não inteiramente adequada é desconstruir a expressão. A desconstrução significa retirar da compreensão e da circulação comum esta expressão e com ela retornar às origens onde ela se gerou. Portanto, desconstruir pode significar despir a expressão de sua universalidade aceita e ressituá-la na nudez e no desamparo de sua origem."26

Não pretendi, propriamente, substituir o aparato conceitual freudiano relativo à angústia com um novo conceito de angústia mas, pela desconstrução, mostrar a rigidez metafísica dos conceitos para deles liberar o que aí estava implícito: os pressupostos não mais metafísicos mas de caráter existencial. Esse trabalho de desconstrução é o que toma propriamente eficaz a aproximação do conceito de angústia da psicanálise, do conceito de angústia da analítica existencial.

Além disso, a aproximação dos pressupostos filosóficos da angústia aos da psicanálise não pretendem levantar, mais uma vez, a polêmica que existe em torno de Freud e da inteligibilidade e validade de seus conceitos, intuídos a partir de um naturalismo biologicista que nunca foi totalmente superado. Mas, apesar de tudo, o novo paradigma que a psicanálise inaugurou na abordagem do patológico deve servir de inspiração, tanto para a antropologia filosófica, como para a psiquiatria. O que vale, portanto, é pontuar alguns novos desdobramentos e implicações dessa nova gramática - a do inconsciente - e em que medida os limites que surgem nas abordagens da psicanálise podem ser amenizadas a partir dos pressupostos filosóficos. De Waelhens, justamente abordando os limites das leituras objetivantes do sujeito sem, no entanto, tentar substituir o paradigma científico pelo filosófico, mas encontrar um espaço onde a objetividade não seja tomada apenas como complementar de ser, mas que seja, sim, um sentido que corresponde plenamente à existência daquele que o exprime, escreve: "Na verdade, essa denúncia pretende inscrever aquele que se nomeia sujeito num outro registro de existência, onde, por exemplo, ser e objetividade não mais sejam tomados como

26 Stein, Ernildo. Regime de construção de objetos e desconstrução da relação de objetos. Veritas, Porto Alegre, v. 43, mar. 1998, p. 120. 
simplesmente sinônimos ou absolutamente complementares, e onde, mais uma vez, o sujeito renuncie a colocar uma certa imagem de si como a origem e o pólo de todos os seus atos. Assim, portanto, há algo por conhecer: a identidade das estruturas significantes e existenciais. Trata-se de um sentido que, ao contrário do sentido do pensamento fenomenológico, coincide em todos os graus, tanto para seu bem como para seu mal, tanto na ilusão como na verdade, com a existência daquele que o exprime. A mesma transcendência que funda a existência como presença em é constituída de sentido. Daí vêm as particularidades da problemática da interpretação próprias da psicanálise", ${ }^{27}$

27 De Waelhens, op. cit., p. 146. 